\title{
Crisis prevention
}

in sub-Saharan

Agriculture: the key to

Africa

\section{the employment challenge}

Bruno LOSCH

In sub-Saharan Africa, 330 million young people will enter the job market over the next 15 years. That is equivalent to the current population of the United States. This influx could be a catalyst for development, provided there is growth that creates employment. Otherwise, there will be major political risks for Africa and the rest of the world.

Yet African economies remain predominantly engaged in agriculture and international competition leaves little scope for rapid economic diversification. Jobs will therefore need to be created on a massive scale in agriculture and the rural sector, especially given that around 200 million of these new workers will live in rural areas.

To address this challenge, as well as that of food security, there is an urgent need to establish areas of priority action aimed at reaching the largest number of people possible. This will mean focusing on family farming, supporting the development of food crops and stepping up rural diversification by strengthening the sustainability of local economies.

\section{perspəctive}

Through Perspective CIRAD provides the opportunity to explore new avenues for discussion and action based on research and expertise, without presenting an institutional position.
Every year 17 million young people enter the job market in sub-Saharan Africa (SSA). This will add up to 330 million by 2025 , or nearly the current population of the United States. And these are not projections: these new workers have already been born. For a medium-sized country such as Senegal, almost 300,000 young people reach working age every year, or 5 million over 15 years (two and a half times the population of Dakar today). This influx is explained by an incomplete demographic transition: the mortality rate is rapidly declining, but the birth rate is falling more slowly, hence sustained population growth (from 2 to $3 \%$ per year for most countries).

\section{The African exception}

While global population growth is a well-known and much discussed phenomenon, particularly with regard to food security, the growth of the labour force is often overlooked. The two are of course connected, with an interval of 15 years corresponding to arrival at working age (15 to 64 years, according to the international standard). SSA is the only region where labour flows will continue to increase after 2050, with 32 million new workers expected at this date. In Europe, East Asia and Latin America, however, flows are now declining; they will decrease in South Asia from 2035 and will stabilise in North America towards 2040. 
The African States

were confronted

with globalisation

just 20 years after

their foundation.

Public policy

must be based on

the regional

distribution of

activities and people.

Agriculture: a far more extensive role than food production alone.
Growth in the working population accompanied by a progressive decline in the birth rate may be an opportunity for economic development, since the burden and cost of the unemployed in the total population falls. This is true provided there are jobs, which depends on the characteristics of the economy, the society and its institutions inherent in the stage of structural change towards a diversified economy (or economic transition), but also on the policies implemented.

In this respect, the situation of SSA is unusual. Although demographic transition has begun and is marked by high population mobility (with an urbanisation rate of $40 \%$, the urban population has increased by a factor of 12 since 1960), the region's economic structure has evolved little: diversification remains low; and agricultural activities still account for a high proportion of GDP, foreign trade and especially employment. Urbanisation has developed without industrialisation, contrary to other parts of the world. This African exception is explained by the historical conditions of the integration of the continent into the global economy, with a late, restrictive, colonial rule resulting in young and small states. These new countries were rapidly projected into the international competition characteristic of globalisation (and into structural adjustment) before they had the opportunity to consolidate their institutions or to implement modernisation policies.

\section{The difficulty of economic diversification}

Diversifying a primary economy (agriculture and mining) in the current context of an increasingly integrated world economy is a real challenge. Past transitions cannot be reproduced, as they were marked by their particular context and especially by the relations of each "national entity" with the world of its time. Thus, the European transitions largely benefited from the hegemonic situation of Western Europe, which enabled growth based on unfair trade (imperialism and colonisation), but also on mass migration, which acted as an outlet for under-employment (60 million Europeans settled in the "new worlds"). And the Latin American and then Asian transitions took place within an international regime characterised by the self-centred national development (import substitution and heavy state intervention) that prevailed prior to the era of globalisation that began in the 1980s.

Countries arriving later on the international scene, such as those of SSA, undoubtedly benefit from numerous advantages as "latecomers" (technical progress, knowledge in terms of institutions and organisations), as well as from the opportunities provided by globalisation (access to new markets and to new supplies of goods, capital, knowledge and know-how). On the other hand, they are faced with many constraints: tougher international competition (competitiveness gaps, loss of local dynamics as a result of imports); challenges to the role of the state; instability of the global economic environment (financial crises); and the limitations of a growth model dependent on the consumption of non-renewable resources, whose consequences will be more and more difficult to manage (climate change, scarcity and conflicts).

These constraints drastically reduce the scope for managing the economic transition towards a more diversified economy capable of meeting the needs of a rapidly growing population. In this regard, South Asia, the other region with a booming working population, is in a more comfortable position due to previous economic diversification, as seen in India, which has a solid industrial and technological base. An additional obstacle for Africa is its division into 50 States, almost all resulting from the colonial period, which weakens the demographic and economic potential of the continent by depriving it of economies of scale in terms of investment and infrastructure, human capital and organisations.

For SSA, by 2025-in other words tomorrow - the development of industry and services will indeed be facilitated by improvements in the economic and institutional environment, increasing labour costs in competitor countries and the opportunities provided by transnational companies offshoring certain activities. But competition will remain more intense and the millions of jobs created according to the most optimistic projections will not be enough to meet the employment challenge. Likewise, international migration can never provide a significant safety valve. Although the ageing populations in Europe and China will gradually bring about changes, liberalisation has not so far been applied to the movement of persons, and restrictive policies should remain the rule over the next 20 years.

Skipping the industrialisation stage and moving directly into the era of cloud computing to invent a new growth regime is one option being discussed, but an unlikely one. In plainer terms, public policy orientations will need to be based on demographic and geographic realities, in other words the regional distribution of activities and people across 
every country: according to current trends, of the 330 million young people who will enter the job market over the next 15 years, two thirds will live in rural areas. This proportion is only expected to reverse after 2035 (see graph below).

\section{Jobseekers in sub-Saharan Africa will be predominantly rural until 2035.}
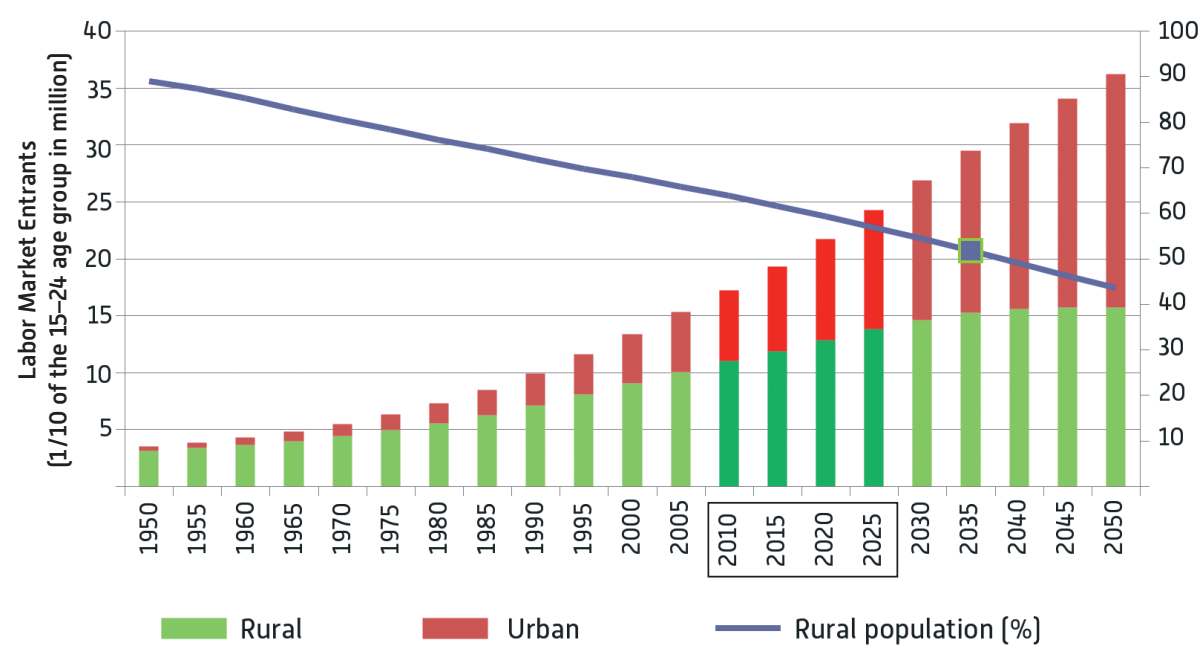

Sources: United Nations, World Urbanization Prospects, 2011 revision, and World Population Prospects, 2010 revision; Losch, Fréguin-Gresh, White (2012).

Development options and technical choices must stimulate employment.

Food security is

the key to economic diversification.

\section{Agriculture, a strategic sector}

Although the SSA countries are heterogeneous, their populations are currently predominantly rural $(65 \%)$ with workers employed primarily in agriculture (60\%), and rural households are strongly engaged in farming (95\%), albeit generally diversified. The rest of the working population is employed in nonfarm informal activities (25 to 30\%), which are mainly urban, and in the formal industrial and service sector (5 to $10 \%$ at most).

Consequently, agricultural and rural development policies must be central to priorities for action. Their failure would hasten rural depopulation, put more pressure on cities and increase local tensions, thereby giving rise to crises and political excesses of all kinds (fundamentalism, insurrections, coups d'État).

Agriculture in the broad sense (including livestock, fisheries and forestry) is a strategic economic sector for developing activities and employment, whether farm or non-farm (upstream and downstream), and for managing natural resources and rural areas: a far more extensive role than the provision of raw materials and foodstuffs, which has been the focus of attention since the food price crisis of 2008 and serves to justify land grabbing.

\section{Prioritising maximum leverage initiatives}

To respond to the huge challenge of employment, the first recommendation is to reinvest in development strategies that articulate a long-term vision and sectoral approaches. These strategies, which have been neglected since the 1980s, must be viewed as genuine public goods, which can as such benefit from support for their development (information systems, training, assistance for negotiations and decision-making). They must associate the different stakeholders involved in public policies: the private sector, local authorities, professional organisations, civil society, and central and regional administrations.

These development strategies need to address long-term structuring issues: sustainability, education, health and productive investment, which condition future adaptability. They are then broken down into sectoral and regional programmes of action. For the agricultural sector and rural areas, the goal is to accompany structural change through the progressive diversification of activities. This diversification will only be possible in response to rural consumer demand, which makes it essential to first improve agricultural producers' income. Generating a virtuous circle of this kind, which will also help to reduce poverty and thereby increase food security, has numerous prerequisites, which are all well known (infrastructure, research, credit, insurance, information and capacity building, etc.), but which are difficult to achieve simultaneously in all areas, especially in the economic and institutional context of most SSA countries.

This is why public action must make proactive choices, while giving free reign to private initiatives. To meet the employment challenge, the pragmatic approach consists in focusing on action that creates the most leverage (through the type of farms and products targeted). The first priority is therefore strengthening family farms rather than large-scale corporate agriculture, since these farms employ the overwhelming majority of agricultural workers, represent the greatest potential for production and employment, and generate the bulk of rural income. This kind of choice comes with specific needs: managing tension over land and water resources using infrastructure and appropriate institutional mechanisms (which stocks of resources and which methods of management?); developing ecologically sustainable and economically viable technical systems (agroecology) adapted to suit poor 


\section{A few words about.}

Bruno Losch is a researcher in political economy at CIRAD UMR Art-Dev (Actors, Resources and Territories in Development, http://recherche.univ-montp3.fr/ artdev/]. He was head of the CIRAD

Family Agriculture programme [1998-2002], then visiting fellow at the Institute of International Studies, University of California, Berkeley. Seconded to the World Bank in Washington from 2005-2011, he set up and coordinated the RuralStruc programme. His work focuses on rural transformation and public development policies. bruno.losch@cirad.f

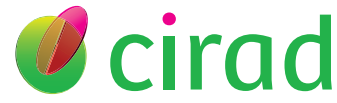

AGRICULTURAL RESEARCH FOR DEVELOPMENT 42, rue Scheffer 75116 Paris. FRANCE

wWw.cirad.fr

Editor: Patrick Caron, Director General in charge of Research and Strategy Coordination: Corinne Cohen, Department for Scientific and Technical Information

Translation: Anna Kiff Graphic design: Patricia Doucet Communication Service Distribution: Christiane Jacquet, Communication Service Email: perspective@cirad.fr farmers and enabling integrated, job-creating intensification (which does not preclude a necessary reduction in arduous working conditions). Foreign private investment can be better directed towards activities upstream and downstream of production, where economic operators and capital are scarce.

The second priority concerns food crops: they have large markets that are rapidly growing (at the regional and international level); they are easy to process locally, foster diversification of activities, and stimulate job creation; and they are cultivated by all farmers, who produce them-at least partly-for their own consumption. Action should focus on improving the functioning of local markets (information systems, transport and storage: post-harvest losses represent 10 to $20 \%$ of production). At the same time, better yields and better access to national and regional markets (which implies a clear commitment to regional integration) make it possible to reduce risks for producers and to unlock the endogenous potential for diversification, both farm and non-farm, including into higher value-added products when the possibility exists.
The third priority is that this kind of approach must be implemented as part of regional policies aimed at reinforcing the urban-rural linkage through the promotion and development of services in small towns and rural districts, which are often overlooked in favour of large cities. Focusing on regional development implies better understanding the local dynamics and strengthening participatory decision-making processes. It also requires public investment and support for private investment in facilities and services, which are essential to the development of small and medium-sized businesses and to the consolidation of the local economic fabric. It will then be possible to strengthen and renew social links and to thereby reduce the risks of conflict over resources.

In the absence of a rapid mobilisation of local, national and international partners on clear priorities and of the means necessary to conduct these policies in the long term, the risks of instability in Africa will continue to grow. Let us not forget that by 2050 , the population of sub-Saharan Africa is likely to exceed that of China by more than 600 million people, and will then be 2.5 times that of Europe.

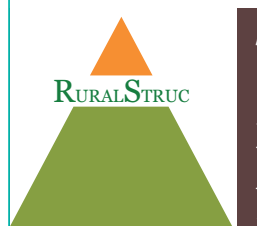

This issue of Perspective is based on some of the findings of the RuralStruc programme, a joint initiative of the World Bank, the French Development Agency, the French Ministries of Foreign Affairs and Agriculture, CIRAD, and the International Fund for Agricultural Development. This programme studied the issue of structural change and rural transformation by developing a comparative approach combining micro analyses (8,000 households surveyed) and a demographic-economic perspective. It involved around 60 experts and researchers in the seven countries taking part in the study, with substantial support from CIRAD with its coordination team (Bruno Losch, Sandrine Fréguin-Gresh, Thierry Giordano) and other researchers directly involved in different stages of the programme, particularly Jean-François Bélières, Jean-Jacques Gabas and Pierre-Marie Bosc.

Among many publications, see notably:

Losch B., Fréguin-Gresh S., White E.T., 2012. Structural Transformation and Rural Change Revisited: Challenges for Late Developing Countries in a Globalizing World. African Development Forum series. Washington DC: World Bank (http://www.worldbank.org/afr/ruralstruc).

Losch B., 2012. "Agriculture and transition in a globalized world". In P. Jacquet, R. K. Pachauri, L. Tubiana (eds.). Development, the environment and food : Towards agricultural change? New Delhi : TERI, p. 61-72.

Gabas J.-J., Losch B., 2008. “Fabrication and Illusions of Emergence.” In Ch. Jaffrelot (ed) Emerging States: The Wellspring of a New World Order. London: C. Hurst \& Co.

Giordano T., Losch B., 2007. «Transition : Risques d'impasse ? » Courrier de la planète (81-82): 22-26.

FIND OUT MORE

Beaujeu R., Kolie R., Sempere J-F., Uhder C., 2011. Transition démographique et emploi en Afrique subsabarienne : comment remettre l'emploi au cœur des politiques de développement. Paris: AFD.

Headey D., Bezemer D. and P. Hazell, 2010. "Agricultural Employment Trends in Asia and Africa: Too Fast or Too Slow?" The World Bank Research Observer, 25(1): 57-89.

OECD, 2012. African Economic Outlook 2012 : Promoting Youth Employment. Paris: OCDE.
Proctor F.J., Lucchesi V., 2012. Small-scale farming and youth in an era of rapid rural change. London/The Hague: IIED/HIVOS.

UNRISD (United Nations Research Institute for Social Development), 2010. Combating Poverty and Inequality. Structural Change, Social Policy and Politics. Geneva: UNRISD.

Van der Geest K., 2010. Rural Youth Employment in Developing Countries: A Global View. FAO Gender, Equity and Rural Employment Division. Rome: FAO. 